\title{
Medical Ethics as a Role Model for Developing Architectural Ethics
}

\author{
TOM SPECTOR \\ Oklahoma State University
}

\begin{abstract}
Although medical ethics seems to be a well-established subdiscipline, the process took some 30 years. We architects can take a number of lessons from the example set by medical ethics as we strive to establish our own sub-discipline.
\end{abstract}

\section{WHAT IS APPLIED ETHICS?}

In a recent essay, philosopher Onora O'Neill observed that applied ethics "differs radically from most other current writing in the humanities and social sciences." ${ }^{11}$ which however non-naturalistic (non-deductive) they may be methodologically, they are still epistemically naturalistic," that is to say, the social sciences strive for descriptive accuracy and avoid making normative judgments about the things described. But applied ethics is different: "Here we have a genre of academic writing that seeks to identify and vindicate normative, actionguiding claims, and then relate them to the facts of situations or cases...So applied ethics aspires to meet the demands both of normative and of truth-oriented, epistemically naturalistic inquiry. Taken together these are heavy demands."2 She goes on to observe that "The distinctive feature of normative work is that its direction of fit is unashamedly the converse of that of empirical or descriptive work that aims at truth claims." ${ }^{3}$

This unique direction of fit is what gives the concept of ethical expertise its controversy and helps account for the reserve held for anyone holding himself out as an ethical expert.

Longtime writer in topic of applied ethics, Tom Beauchamp, summarizes: "Applied Ethics" is now used to refer broadly to any use of methods of reasoning to critically examine practical moral decisions and to treat fundamentally moral problems in the professions, technology, public policy, and the like."4 Despite this direction of fit that O'Neill discusses, we should, however, be on guard against the idea that applied ethics is always a one-way street between established philosophic principles and positions on the one hand that are applied to moral problems on the other. It can be more complicated than that.

Exactly how decision makers apply concepts derived out of moral philosophy is in itself a rich discussion in the field.

Some observers have argued that moral philosophy is mainly used as a commentary on the common morality of a culture which all concerned people share and which serves as the real source of normative authority. This "common morality" model solves the problem of deciding between competing moral theories by demoting them all equally and probably squares well with the way many dilemmas are handled in everyday life. It acknowledges that most competent moral judges do not know Kant or Mill. Critics of the "common morality" position think this explanation undesirably idealizes common morality while rendering it both static and impenetrable. Throughout most of history, for example, slavery was considered entirely legitimate by concerned people within the common morality of their cultures. If common morality is bedrock, then how are such mistakes redressed?

This concern has led such important observers as Baker and McCullough to assert, instead, the importance of the appropriation model of applied ethics. In this model, moral philosophy does impact directly in decision making, but in pieces, not wholesale. Since the medical field is the most notable field preceding us down the road of applied ethics, my remarks will draw on the examples it sets. No one asserts, for instance, that the intricacies of the Grounding for the Metaphysic of Morals are assimilated by doctors in a moral quandary, or even their ethics committees. Instead, those dealing with dilemmas in their field filch snippets from moral philosophy to help them generalize from individual instances.

Appropriation may go so far as transforming the ideas of the original writers as it progresses and builds upon itself. This is the case with the use of the important term, autonomy, which has very specific requirements in Kant but was used quite differently in the milestone Belmont Report on human subject research in 1978 which became an authoritative summation of earlier piecemeal policy work on the same topic. "On the appropriation model, transformations in the process of adapting philosophical concepts are the core of innovation in practical ethics. It simply beggars belief to assume that the scholars involved in drafting the Belmont Report-Tom Beauchamp, James Childress, Albert Jonsen, Karen Lebacqz, RobertLevine, Stephen Toulmin, and LeRoy Walters, to name a few-committed a sophomoric error in using Kantian terminology. It is more reasonable to assume that the Belmont authors adapted Kantian conceptions to the problem at hand." 5 This view is validated by one of the Belmont Report's authors: "We took a sliver from the timber of Kant's mind and reconceptualtized it in the context of the problem posed by research with human subjects."6

The appropriation model authorizes ethical experts and moral decision makers, pragmatically in regard to philosophy, to "take from it what you need; make of it what you want." 


\section{WHAT IS THE FUNCTION OF ETHICAL EXPERTISE?}

To dissect, for a moment, the nature of ethical expertise and its function, it is useful to distinguish between two types of expertise:

First there's epistemic expertise: the ability to provide robust justifications for one's opinion. This differs from

Performative expertise: the ability to perform a task well; for instance, the ability to live a morally good life.

Now clearly epistemic expertise is required in the ability to, say, connect commonalities between prima facie moral dilemmas and the prescriptions of ethical theories. I am looking forward to experiencing many instances of just such epistemic expertise in the next few days.

This epistemic expertise can certainly reflect the acquisition and mastery of difficult knowledge bases unavailable to the non-expert public.

Epistemic expertise, however, as we know, does not automatically translate into skill at providing normative judgment, which is, after all, ultimately what is needed. This is what makes critics of the notion of ethical expertise suspicious because, they say, "normative reasoning is closely associated with substantial moral conclusions and (only) relatively loosely connected to factual conditions"7 That is to say, the basis for judgment is only partly dependent on the possession of epistemic expertise. More to the point: knowledge of moral philosophy is no guarantee AT ALL that one knows when and how to apply theory. Thus, notwithstanding the significance of the role of ethicists in contemporary public life, the concept of ethical expertise has been, and continues to be, controversial. Frey sums up, "Some have asked whether expertise is possible at all in relation to moral questions, and, if so, whether it is morally and politically desirable to credit select individuals with an expert status in these questions (Cowley 2005; Varelius 2007)." ${ }^{8}$ Ethical expertise may seem overly sophisticated when it is generally agreed that one need not be an ethical expert to be a competent moral decision maker.

This concern would be highly justified if the function of ethical experts in medicine were to take the decision making away from the doctors, but this is not characteristically how the expertise is used.

The practice of medical ethics stays clear of this problem by eschewing the role of decision maker in favor of "advising and facilitating as core competencies of ethics consultants" ${ }^{\prime \prime}$ This role is delineated, for example, in Great Britain by the Royal College of Physicians.

In medicine, the decision making primary care physician is considered morally capable, and indeed, usually required to take the ultimate responsibility for difficult decisions due to his or her medical skill and presumably intimate knowledge of the given situation. The ethical expert doesn't usurp the role of decision maker but rather as facilitator may help the decision maker to consider, for example, how decisions were arrived at in morally similar situations, the sorts of theory that underlie a given position, to help them tease out the relevant facts of the situation from the extraneous, and to help them verbalize the decision-making criteria. On occasions, ethical expert opinion may be asked to weigh in with an actual judgment and this may be particularly relevant in dramatic rehearsals of imaginary, but easily imagined, situations in anticipation of needing to make such decisions in less than advantageous and less than leisurely circumstances, which moral deliberation or reflection, by its very nature, requires. If it's arrived at quickly, it simply isn't deliberation.

(It may well be moral judgment.)

This role seems to me as relevant and desirable for architecture as it is for the medical profession.

Institutionally, "Ethicists are chairpersons and members of ethics committees. They facilitate moral deliberations on hospital wards; give advice to individual professionals on how to interpret and manage morally difficult situations; and teach ethics to students, interns, and residents. Ethicists also serve as expert witnesses in court, especially in the United States (Nussbaum 2002)."10

It's not too much of a stretch to see that some of these same sorts of opportunities might exist in the field of architecture. We don't have the equivalent of hospital wards, nor of bioethical experiments; on the other hand, by its very imbeddedness in a multiplicity of other fields, ethical experts in architecture will find uses for themselves not contemplated in medicine.

\section{HOW DOES APPLIED ETHICS GO FROM A MERE INTEREST TO A SUBFIELD?}

The lack of an established discipline in architecture isn't necessarily a cause for hand-wringing. The widespread acceptance of applied ethics in medicine took awhile to secure. Although the Cambridge World History of Medical Ethics charts the field's beginnings to the 12th Century, the modern conception of medical ethics as a field in itself is of considerably more recent vintage. To be sure, we will find differences in different countries, but in Britain, one man, Ted Shotter, a Church of England chaplain, is given originating credit when he began organizing ethics studies groups for medical students throughout England in the 1960s. As those students matured into the profession, a senior group eventually coalesced into the Institute for Medical Ethics. Volume 1 no1 of the Journal of Medical Ethics, edited by Shotter, appeared in 1975. Though not yet institutionalized in the schools or in the profession, it seems fair to observe that the field was well-formed and 


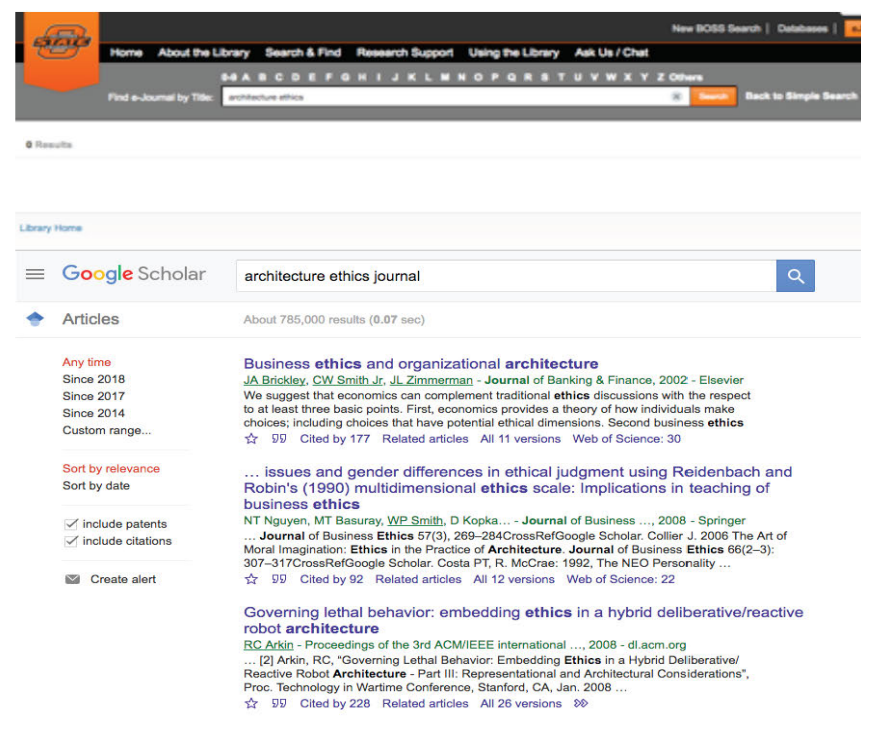

Figure 1: Your search returned 0 results

self-aware just 4 years later in 1979 with the publication of Beauchamp and Childress' book Principles of Biomedical Ethics. Widespread institutional recognition and professionalization didn't occur until the 1990s. In 1993, Britain's General Medical Council required medical ethics as a core subject-a widely ignored mandate at the time but evidence of a crumbling resistance nonetheless. Not until 1998 was a consensus statement among medical schools published indicating widespread implementation of ethics education in the medical schools. Thus, we can say that it took 40 years for the field to fully arrive from its beginnings in discussion groups. In the inaugural editorial of 1975, the editors of JME expressed an enthusiasm for the nascent field that I think might just as well apply as a guide to shaping the field of design ethics in the built environment. They wrote "The most fascinating aspect of medical ethics in the broad sense is that controversies within its boundaries can be most acute just where knowledge, skill, and enthusiasm are at their most advanced." ${ }^{11}$ As a starting point, I think we could do little better.

By any measure, the field has blossomed and matured. A look at the database of full text journals on medical ethics will turn up not only the venerable Journal of Medical Ethics, but also such titles as BMCMedical Ethics, the Indian Journal of Medical Ethics, Issues in Medical Ethics, Medical Ethics Newsletter, Bioethics, Journal of Clinical Ethics, Theoretical Medicine and Bioethics, Cambridge Quarterly of Healthcare Ethics and even the mouthful entitled Social Science and Medicine, Part F, Medical and Social Ethics. And more besides.

There are even several crossover journals between medical and legal ethics such as The Internet Journal of Law, Healthcare and Ethics, The Journal of Law, Medicine and Ethics, and the Yale Journal of Health Policy, Law.
A search for the keywords "Architecture, Ethics" or "architectural ethics" turns up 0 records.

This dearth of journals in architectural ethics is both telling and important.

This is not to say that there hasn't been a steady trickle of books and articles over the last 10 years that might, ultimately, amount to helping inaugurate a field. But what has been most lacking, so far, is a sense of the existence of a discipline. It seems everyone is still fanning-out, horizontally, as it were, to explore and stake out new territory. So, for example, while my book in the early part of the century was a fairly straightforward attempt at applied philosophy, Karsten Harries slightly earlier The Ethical Function of Architecture sought to establish a new grounding in the Heideggerian sense. Whereas the more recent edited volume by Gregory Caicco Architecture, Ethics, and the Personhood of Place brought together a diverse group that had apparently never heard of either book (except for the participation of Harries himself in one essay) nor of Warwick Fox's edited book that came out of the first EBE conference nor of Nick Ray's edited volume emanating from the 2004 conference at he organized at Cambridge. The even more recent book by Robert Mugerauer and Lynne Manzo Environmental Dilemmas: Ethical Decision Making seeks to establish itself as a textbook for the various environmental design occupations but displays little awareness of the 1990s text Ethics and the Practice of Architecture, by Barry Wasserman and his associates. My point being that, while we can find a steady stream of books, what is singularly lacking is a VERTICAL sense of the subject, a sense that work has been done that could be responded to, improved on, and furthered. Each outing appears to be a stand-alone. Thus, I dare to gripe at this juncture only partly out of disappointment but mostly because it seems, finally, and at last, with this conference, we have an opportunity to actually reflect and build on the efforts of a decade ago, to take stock and perhaps get a sense of the shape such a field might take.

This is why, I think, the absence of a journal in the budding field is so telling and so important. A journal still appears to be the best vehicle for a field or sub-field to get a sense of itself, to establish its boundaries and turf, and to ignite the ongoing conversation necessary for a mere interest to become a field.

The veritable explosion of journals in medical and bioethics tells of a robust conversation, several robust conversations actually; too many to fit the confines of a single journal.

Drawing a few conclusions from the past 34 years of JME, it appears important that a sub-field have both its durable topics as well as its evolving ones. Durable topics in medical ethics that could easily relate to architectural ethics include such subjects as: 
Issues of scarcity: including prioritization of care-allocations, rationing, and distribution-as well as the sometimes hotbutton topic of organ donation. In architecture scarcity takes the form of land, amenity, sunlight, energy use. The list is long.

Pedagogy: how medical ethics should be taught. Architecture has similar questions-how does ethics fit into an already crowded curriculum?

Information \& power disparities: in the medical field these take the form of concern over paternalism, competence to decide, and informed consent. In architecture it takes the form of alienated and underserved populations.

Confidentiality: its limits and purpose. Not as crucial in architecture but still relevant.

Multiple Perspectives: Examinations of diverse points of view which in medical ethics takes the form of those of physicians, nurses, and students, primarily, but in architecture would certainly embrace the even more disparate points of view of architects, contractors, engineers, developers, regulators, end users and segments of the larger public.

Some areas of discussion would be discipline specific. In the case of medical ethics discipline specific areas include:

End of life issues, euthanasia and vegetative states.

Beginning of life issues and surrogacy.

Abortion

The role and function of ethics committees in research and in approving experimental procedures.

Genetic engineering.

Clinical trials.

Role of religion in medical decisions.

Architecture would have its own discipline-specific discussion such as:

How wide a net of consequences must an ethically motivated architect consider in both geography as well as time?

What is an ethical attitude toward the design of detention facilities?

To what degree are sustainability, global warming, homelessness, and other large-scale ills architectural problems?

Another durable strand of conversation in medical ethics runs the opposite direction: rather than employing ethical theory to help sort out difficult medical issues, it employs difficult medical issues to illuminate meta-ethical arguments.

Some examples from JME:

"The multiple self objection to the prudential lifespan account"

"Defense of Kant's moral prohibition on suicide"

"Is truth a supreme value?"

Some really stretch the bounds of what one would expect in a medical journal, for example, "The tension between self governance and absolute inner worth in Kant's moral philosophy"

This title made me feel like I was looking in on a banquet while starving: "How medical ethicists decide which medical ethics journal to submit to." !!

This one should be incredibly brief: "Should physicians be allowed to use alcohol while on call?" NO!

Some hot-button issues, as one might imagine, at the journal's inception have become routine to the point that, lacking further technological advances, they no longer merit discussion:

In vitro-fertilization has become old hat, as has organ transplantation. Discussion of the ethics of stem cell research, cloning, and genetic engineering seem to have peaked as topics.

This recalls Richard Rorty's wry observation that philosophy never solves anything, it just renders some questions uninteresting.

To add spice, a journal needs some oddball juicy titles: "The challenge of 'sperm ships': the need for the global regulation of medical technology"-ok, so in vitro fertilization hasn't gone away completely.

And the occasionally scary title: "Bach to the future: Response to: Extending preimplantation genetic diagnosis: Medical and non-medical uses" this one needs its own medical intervention in the form of a colonectomy.

The existence of a journal permits a retrospective on long term changes in focus. Looking back on his tenure, a retiring editor of JME observed that the foci of medical ethics in the 60 s was on beneficence and non-maleficence while respect for autonomy dominated the agenda in the self-absorbed 70 s and 80s. Concern for justice or social justice seemed to be the driving force behind developments in medical ethics in the 90 s and beyond. 
What you will not find in the Journal of Medical Ethics, and its a stance with which I wholeheartedly agree, is any interest in uncovering the Unethical, that is to say, instances of poor behavior; opportunities to castigate someone. This sort of inquiry will get us nowhere.

No doubt there are important asymmetries between architecture and medicine that would bear relevance to the performance of architectural ethical expertise. To begin with, it may be worth asking if the problems and issues in medical ethics didn't come to the field more well-formed than do ours. The medical field, at least from the benefit of hindsight, had a number of juicy problems that fit squarely within the purview, responsibility and consideration of practicing professionals. Furthermore, the results or consequences of practitioners' actions tend to become observable relatively quickly compared to our field. Thus, there was little worry at the outset that topics in medical ethics might be elusive, ill-defined, or lack relevance. This is perhaps both a source of interest and bedevilment to an emerging study of architectural ethics: the ripple effect from practitioners' actions goes on for so long and effects so many people in so many potentially different ways, that an important service we may try to address is just how to constrain consideration of the import of one's actions, in an ethically defensible way, so that consideration of outcomes doesn't become paralyzing and vertiginous. Physicians tend to be more directly in charge of the actions that materially affect people's well-being than do architects, and tend to see the results directly. On the other hand, the very embeddedness of architecture within such a broad sweep of overlapping imperatives, emanating from the construction economy, environmental awareness, cultural issues, the list goes on,--can you think of another field that makes so many connections?-ought to prove a source of lively discussion for a long time to come.

This notion dovetails rather well, it seems to me, with O'Neill's prescription for the future of applied ethics. She writes: "practical ethics can go beyond the consideration of principles and the types of situations in which they could or should be applied by saying more about the institutional structures and cultural support needed if respect for significant ethical and other principles is to be adequately achieved in public, professional and private life. It could, for example, focus more on ways in which systems of accountability could be structured to support rather than undermine the intelligent placing and refusal of trust or on shaping institutional structures that can secure and allocate the obligations needed if human rights are to be taken seriously. It could say more about ways in which supposed rights to freedom of expression can - or cannot be reconciled with intellectual property regimes. It could say more about the relevance - or inadequacy - of demands for transparency in improving communication and public policy. It could say more about better and worse ways of constructing regulatory regimes to secure and support compliance with ethical principles. These are rich pastures, and those of us who take normative reasoning seriously could explore them." (229).

These suggestions I find to be particularly heartening because it makes a virtue rather than a liability out of a field's embeddedness in a culture. The multiplicity of connections architecture makes can be just the sort of rich pastures $\mathrm{O}^{\prime}$ Neill envisions.

Thus, rather than be disheartened that architecture lags so far behind other fields in ethical development, we can instead use their achievements to springboard our own discipline, that is, if we want one.

Still, we have 0 records.

\section{ENDNOTES}

1 O'nora O'Neill “Applied Ethics: Naturalism, Normativity and Public Policy” Journal of Applied Philosophy v26 n3 August, 2009, 219-230. 220

2 O’Neil, 223.

3 O'Neil, 224.

4 T. L. Beauchamp, "History and Theory in 'Applied Ethics'". Kennedy Institute of Ethics Journal, 2007 Mar;17(1):54-64. 54.

5 NL Steinkamp, B. Gordijn, and HA ten Have, "Debating Ethical Expertise." Kennedy Institute of Ethics Journal. 2008 Jun;18(2):173-92.

6 Beauchamp, 54.

7 Steinkamp, 178.

8 R. G. Frey and Christopher Wellman. A Companion to Applied Ethics. (Oxford: Blackwell Companions to Philosophy. 2003), 173.

9 (Frey, 180)

10 (Frey,173)

11 Journal of Medical Ethics, "Ethics and the Professions" BMJ Publishing Group Ltd \& Institute of Medical Ethics, n1v1 1975, 2.

12 O'Neill, 229.

\section{REFERENCES}

Belmont Report: National Commission for the Protection of Human Subject of Biomedical and Behavioral Research 1979. http://ohsr.od.nih.gov/guidelines/belmont.html

Beauchamp, Tom and Childress, James. Principles of Biomedical Ethics. (New York: Oxford University Press, 1979).

Baker, Robert B. and McCullough, Laurence B. Cambridge World History of Medical Ethics. V1\&2, Cambridge University Press, 2009.

\section{Architectural Ethics works cited:}

Harries, Karsten. The Ethical Function of Architecture. (Cambridge, MA: MIT Press, 1997).

Wasserman, Barry. Sullivan, Patrick and Palermo, Gregory. Ethics and the Practice of Architecture. (New York: Wiley, 2000).

Fox, Warwick. Ed. Ethics and the Built Environment. (New York: Routledge. 2000). Ray, Nicholas. Ed. Architecture and its Ethical Dilemmas. (London: Taylor \& Francis, 2005).

Caicco, Gregory, ed. Architecture, Ethics and the Personhood of Place. (Lebanon, NH: University Press of New England, 2007).

Mugerauer, Robert and Manzo, Lynn. Environmental Dilemmas: Ethical Decision Making. (Lanham, MD: Lexington Books, 2008).

Spector, Tom. The Ethical Architect: The Dilemma of Contemporary Practice. (New York: Princeton Architectural Press, 2001). 